\title{
Being Disruptive: How Open Growth is Delivering Effective Social Change at a Fast Pace
}

\author{
Elisha Muskat and Delyse Sylvester
}

"Every successful organization has to make the transition from a world"
defined primarily by repetition to one primarily defined by change.
[...W]e must migrate rapidly to becoming a global "team of teams"
that comes together in whatever combination necessary to add the
greatest value. [This] would be almost impossible without the web and
its associated communications tools. Three people in the remotest
corner of the world can decide to bring change to their community,
have access to all the ideas and tools available in the world, and
contribute to experimentation and successful change making. Ashoka's
Changemakers pioneered open-source problem solving for the many
interests involved in change making.

Bill Drayton

Founder of Ashoka: Innovators for the Public

\begin{abstract}
Both innovators and funders need tools that map the entire constellation of solutions in a sector. Innovators, often labeled and isolated as system disruptors, need to be linked with their global peers offering and seeking each others proven strategies to accelerate positive change. The impact investing space needs a simple, open, and transparent way to find, convene, support, and track the progress of innovators.

This article describes how the Ashoka Changemakers.com online community creates a space for: investors to find and support multiple innovations; social innovators to find each other, work together, and source funds; and disruptive innovations to grow over time where disruptive change is needed, fast. Crowd-sourcing, transparency, and open growth are keys to accelerating large-scale change and creating a world of changemakers.
\end{abstract}

\section{Introduction}

Social entrepreneurs and innovators are creating and implementing disruptive solutions that are leading to much-needed, lasting social change. Doing so takes time and focus - which can result in a very nose-to-theground approach. Coming up for air to seek out opportunities for collaboration and new types of support is crucial to scaling the impact of one's work, but can often be low down on a long list of priorities. Online social platforms can help social innovators achieve scale, but only if they are usable and accessible.

At the same time, many investors and funders are busy implementing their processes for selecting the projects they will support in a given cycle. These processes help create rigour, fairness, and consistency. But they only work to find those projects that best meet existing criteria, leaving many amazing projects in the "no" or "not now" pile. Investors, like innovators, stand to benefit from more reflective and collaborative processes, and the same online social platforms can help them find new solutions and trends.

Ashoka's Changemakers.com has, for the last 14 years, been serving as that accessible platform to address these issues: open-sourcing solutions to thematic challenges, creating opportunity for collaboration, and trend-spotting. (See changemakers.com/timeline for a more detailed history of Ashoka's Changemakers.) In its new- 


\section{How Open Growth is Delivering Effective Social Change at a Fast Pace}

Elisha Muskat and Delyse Sylvester

est iteration, Changemakers.com is creating a marketplace that will also address the question of what to do with the projects "left in the pile". It is allowing investors to go beyond their "top 5" by creating growth funds that can be invested in "change-shops" within the larger marketplace.

\section{Collaborative Entrepreneurship}

The rapid pace of change and increasing pressures on our climate, economy, political institutions, and global resources are disruptions with potent negative consequences. They demand equally potent positive disruptions - and fast. Individual social entrepreneurs are an unstoppable force of social change, but that force multiplies when social entrepreneurs come together to solve problems collectively. Collaborative entrepreneurship better leverages the value of local resources and global networks to more effectively scale social innovations.

It is surprisingly difficult for social entrepreneurs and investors to embrace new technologies for social impact. Exploring the countless web-based social change platforms remains a third-tier priority for social entrepreneurs because most are busy keeping the lights on; they are on the ground, face-to-face with the people whose lives they hope to change, staring challenges such as poverty and homelessness square in the eye.

Similarly, using web-based social change platforms is not a priority for most investors because their established granting systems get the job done - traditional grant applications, which require a large amount of time to prepare and submit, continue to stack high on funders' desks. But those same funders, faced with limited grant quotas and staff pressed to capacity just cannot get to all the promising ideas left in the pile.

To respond to this need, Ashoka Changemakers has created an online community that allows any user to pitch their ideas for social change. The best solutions, which range from idea-phase innovations to those with proven system-changing potential, receive unrestricted funding to scale-up their programs. The application process is relatively simple: users fill out an online application (in English, French, Spanish, or Portuguese with an ever-expanding list of languages), explaining what they do, how it is new, what the impact is, and how it is sustainable. These project plans are submitted to live competitions hosted by sponsors. The innovat- ors get the chance to interact and collaborate (with each other and the larger community) and all-thewhile, the Changemakers team is in the background identifying trends and patterns to highlight to investors.

When innovators come together, there is instant recognition that they are a collective force for change. Rather than funders making vertical decisions for individual projects or programs, funders could be working across sectors. As Marilyn Struthers, program manager for the Ontario Trillium Foundation, stated: "Seeing funders as part of a funding economy can help us to make a strategic shift from looking down [into specific projects] to looking across the landscape for collaborative opportunity [for more systemic shifts]."

\section{From Open Source to Open Growth}

The Changemakers model of open-sourcing innovation has been an incredibly powerful tool for bringing together some of the best global ideas on a particular theme. This model embraces the principles of transparency and collaboration to create an online environment that supports the co-creation and evolution of innovative ideas; innovators can freely and openly share what they are doing and comment on what others are doing to co-create solutions to an identified global challenge. However, it was also leaving some ideas in the untouched pile, and falling short in providing ongoing support for emerging collaborative innovations. So, in 2012, Changemakers launched its newest iteration based on "Open Growth" (still in beta).

Open Growth extends the open-sourcing concept beyond identifying innovation, into growing innovations. Rather than simply posting an idea or project online, social innovators can share their plans for growth and scale, identifying key milestones and tracking their achievements in real time. Each innovation serves as a shop - more specifically, a change shop - in a marketplace of innovations. Investors can stroll through the marketplace, supporting as many change shops as they please.

Through change shops, social entrepreneurs are transparently defining and reporting on the progress they have achieved with their projects, from the first spark of inspiration to action. Simultaneously, funders can track the progress of innovations they invest in, and they can clearly measure the effectiveness of their efforts. Already, more than 800 idealists, innovators, entrepren- 


\section{How Open Growth is Delivering Effective Social Change at a Fast Pace}

Elisha Muskat and Delyse Sylvester

eurs, and organizations have set up shop on Changemakers.com - and 35 new change shops are being launched each week.

Through Open Growth, Ashoka's Changemakers is creating transparency and dynamic interaction between stakeholders - social entrepreneurs and investors alike.

\section{Open Growth Example 1: Collaborating in First Nations Communities}

Wapikoni Mobile (wapikoni.tv) is a social enterprise based in Montreal that has created a change shop. Wapikoni is not a typical brick-and-mortar venture. It is a traveling studio, created by filmmaker and Ashoka Fellow Manon Barbeau in 2004, that operates out of an RV and trains youngsters from First Nations communities in audiovisual and music creation. It encourages expression through art - an important medium for a culture that relies on oral tradition for storytelling.

Many youth growing up in First Nations communities do not have it easy. They face elevated school drop-out rates, alcoholism, isolation, and their suicide rate is twice the national average (tinyurl.com $/ 6 \mathrm{~m} 2 \mathrm{srwc}$ ). Wapikoni fills a tremendous need for a too-often marginalized population by providing at-risk youth the opportunity to be mentored by professional filmmakers and community organizers.

Since its inception, the mobile studio has reached more than 2,000 young people from seven First Nations, in 19 communities. These once-marginalized youngsters have produced 450 short films, 350 musical compositions, and have taken home 50 awards from film festivals in Canada and abroad.

The latest gadgets can surely help Wapikoni improve the quality of its services - high definition video cameras and recording studio apps are more affordable than ever - but it is the intersection between new tech and supportive online spaces, an open-sourced approach, that will help social entrepreneurs like Barbeau grow to the next level of change.

The pursuit of new feedback and funding models drew Barbeau to the Changemakers online community. Ashoka Canada had partnered with a large group of philanthropic and citizen-sector organizations to run a Changemakers competition to surface solutions for improving the learning environment of First Nations, Métis, and Inuit Peoples in Canada.
Barbeau submitted an entry to the "Inspiring Approaches to First Nation, Métis and Inuit Learning" initiative. Barbeau and Wapikoni were identified by the Changemakers community from a pool of nearly 300 entries for a pair of growth prizes, including a $\$ 2,500$ award from the Donner Canadian Foundation.

But what Barbeau never anticipated when she submitted her entry was the establishment of a long-term partnership with another Canadian social venture, Aboriginal Student Links (aboriginalstudentlinks.ca), a winner of the "Inspiring Approaches" Martin Aboriginal Education Initiative Award. Barbeau met Doug Dokis in a 90-minute Google+ Hangout (tinyurl.com/7hd7t3l) hosted by Ashoka Changemakers as a part of the Open Growth strategy; the Hangout provided entrants with a fun, open, and collaborative online space to meet other innovators and think through barriers to development with a social change lens.

Doug Dokis manages community services and outreach for Aboriginal Student Links, a venture that creates leadership capacity among students of all ages through a chain of long-term mentorship opportunities, from one class of participants to the next. In an interview, Dokis described the pressures of working as a social innovator, and the opportunities that the open-source approach opened up for him. "There is so much going on in the day-to-day that, typically, you only look in the places and toward the people you're familiar with. We're isolated in our areas of work. Without the online community on the site, I would never have heard of many of the programs that were involved in the initiative. It created opportunities to share ideas, form relationships, build partnerships, and even improve our programming."

Barbeau and Dokis, despite not knowing each other beforehand, quickly realized that the missions behind their ventures were not isolated at all, but rather aligned quite closely - thanks to convenient and affordable technology, in this case a live video conference. The two jumped at the chance to work together to improve the lives of youth in Canada.

Together, Wapikoni and Aboriginal Student Links are documenting student development and empowering the next generation of First Nations leaders. Perhaps more important, however, Open Growth also gave Wapikoni Mobile and Aboriginal Student Links access to funding opportunities that are not readily available for social entrepreneurs in Canada. 


\section{How Open Growth is Delivering Effective Social Change at a Fast Pace}

Elisha Muskat and Delyse Sylvester

"The impact our programs have on the kids is incredible," Dokis said. "It's amazing to watch: if you provide youth with one meaningful adult in their life, they can change theirs. Our students are seeing that first hand.

"But in today's funding landscape, it's becoming more and more difficult to sustain programs. We're very dependent on provincial funding and, to a lesser degree, federal funding, so I was happy to see that there was a significant corporate and philanthropic involvement with the Inspiring Approaches initiative."

\section{Addressing the Challenges of Old Processes}

It is partly due to Open Growth, the public-facing online space, that emerging and established social entrepreneurs are able to better connect with each other, and to new capital, and to more effectively solve social problems. The more transparent innovators will have the greatest success in attracting funding and partnerships. The most engaged and adventurous investors will be most successful in leading the field in funding system change and impact.

No longer must funders decide to support one idea, while passing over other worthy solutions - a frequent funding conundrum that further silos agents of change. Now, opportunities for funders can shift from the embrace of proven solutions into venture capital investment in cutting edge ideas with potential for system change over five to ten years.

Successful Open Growth partnerships will compel other innovators to follow suit and will drive shifts in policy - or simply preempt them altogether. Already Open Growth has demonstrated its enormous potential to tap into and spread the innovations that have impact on their own, but are gamechanging if championed on an even greater scale.

\section{Open Growth Example 2: Positive Disrup- tions in Business in Developing Countries}

In 2010, the G20 asked Ashoka to use Changemakers to open-source solutions from around the world (tinyurl.com/76hsjum). They were looking for the best initiatives that had the capacity to unlock financing for small and medium-size enterprises (SMEs) in developing countries that are traditionally shut out of commercial lending and investments, despite their significant role in fueling economic growth.
Of hundreds of entries from around the world vying for G20 investment that will permit them to scale-up, 12 were chosen to take the stage at the G20 Summit and stand alongside U.S. President Barack Obama, Korean President Lee Myung-bak, and Canadian Prime Minister Stephen Harper.

Together, with involvement from the Inter-American Development Bank (IDB), these global leaders launched an SME Finance Innovation Fund and committed a total of US $\$ 528$ million to support the fund (tinyurl.com/7cdnua2). Open Growth will play a key role in further developing this innovative approach at the G20 Summit in Mexico, and it will attract little-known disruptive innovations that will continue to usher in new ways of doing business.

These previously unheralded, independent, grassroots solutions are unconnected to top-down policy and are not burdened by government restrictions or bureaucracy. Through the open process, they became the leading edge of the G20's approach to addressing this major economic problem that had been hindering a global economic recovery.

One of the winners, Building Markets (buildingmarkets.org; formerly Peace Dividend Trust) was instantly put on the world stage, given a sizable investment, found partnerships and opportunities to scale rapidly, and became a global force for growing sustainable SMEs in conflict-ridden and post-conflict countries that were previously relying on economy-stunting foreign aid and external contractors. In addition to this, Building Markets founder, Scott Gilmore, was then identified as a leading social entrepreneur and has since been elected as a Senior Ashoka Fellow in Canada, recognizing the impact he has made on a continental scale.

\section{Conclusion}

The world is teeming with social innovations that have the potential to rebuild systems that define the way we live. Innovators who will have the greatest impact are passionate and focused, but also pause to identify opportunities for collaboration and strategic partnerships. Ashoka's Changemakers platform provides a place where innovators can easily share their ideas in an open marketplace and track their progress towards achieving change. As innovators share their ideas, their work, and their progress, investors can see this in real time, helping to inform decisions about how to invest capital or granting dollars. 


\section{How Open Growth is Delivering Effective Social Change at a Fast Pace}

\section{Elisha Muskat and Delyse Sylvester}

Our times are marked by dizzying and sometimes frightening change. Entrepreneurs and investors demand the fast, effective, and collaborative action that Open Growth has the potential to deliver.

Ashoka envisions a world where everyone is a changemaker; a world where every individual - whether an SME accelerator presenting on stage at the G20, or a young documentarian in Quebec - has the skills, tools, and societal support to create positive change around them. Ashoka has built Changemakers to help create that enabling environment, and each new iteration provides better skills, tools and support to create a world of changemakers.

\section{Recommended Reading}

- Scaling Social Impact by Giving Away Value tinyurl.com/83rpqqe

- Just How Powerful Are You? tinyurl.com/cee72yk

- The Challenges of Measuring Social Impact tinyurl.com/78yrgu8

Citation: Muskat, E. and D. Sylvester. 2012. Being Disruptive: How Open Growth is Delivering Effective Social Change at a Fast Pace. Technology Innovation Management Review. July 2012: 16-20.

\section{About the Authors}

Elisha Muskat is the Executive Director of Ashoka Canada. Prior to joining Ashoka in 2009, where Elisha became absorbed in the systemic change approach at the core of Ashoka's work, she worked primarily in youth development, running programs in Toronto, New York City, and Syracuse. She has also launched conflict-resolution and peer-mediation programs and developed a green business advisory for small business owners. Elisha has an MBA from Schulich School of Business at York University and a BA in Psychology from McGill University.

Delyse Sylvester is the Director of Community at Ashoka Changemakers. Delyse has been committed to social change for three decades in a variety of fields including fair trade, conflict resolution, deforestation, and domestic abuse, through volunteer organizations, NGOs, advocacy groups, and universities. She has put this broad experience to work at Ashoka Changemakers, building innovative cross-sector collaborations, online awareness campaigns, and tools that advance the impact of social entrepreneurs around the world. Delyse also addresses conflict and injustice as a board member at Inter Pares. 